\title{
Um estado emotivo: representação da gravidez na mídia*
}

\author{
Claudia Barcellos Rezende**
}

\begin{abstract}
Resumo
Este artigo analisa o modo como a gestação é tratada na Revista da Gestante - em particular a visão de um processo que pode ser em grande parte controlado pela gestante. Nessa publicação as reportagens fornecem, através de um discurso prescritivo, "dicas" para uma gravidez "tranquila e feliz". O foco das matérias é a percepção de uma natureza emotiva à gravidez, durante a qual os sentimentos de medo e ansiedade seriam recorrentes. Através da análise dos sentimentos tematizados, destaco uma visão da gestante como agente autônomo e relativamente isolada do seu círculo social, a não ser pela estreita relação com os especialistas médicos. Consequentemente, o problema do controle de si e das emoções, tema caro às sociedades ocidentais modernas, torna-se uma questão para a gestante.
\end{abstract}

Palavras-chave: Gravidez, Mídia, Emoção.

\footnotetext{
" Recebido para publicação em março de 2009, aceito em dezembro de 2010.

** Professora adjunta do Departamento de Ciências Sociais da UERJ. cbrezende@bighost.com.br
}

cadernos pagu (36), janeiro-junho de 2011:315-344. 
Um estado emotivo: representação da gravidez na mídia

An Emotional Estate: Representations of Pregnancy in the Media

\begin{abstract}
This article examines the representations of pregnancy in the magazine Revista da Gestante, particularly the notion that this is a process that may be to a large extent controlled by pregnant women. In this magazine, articles present a prescriptive discourse, with "tips" to a "happy and calm" pregnancy. They focus on the idea that pregnancy has an emotional nature, especially due to the frequent sentiments of fear and anxiety. By analyzing these emotions, I argue that pregnant women are seen as autonomous agents who are relatively isolated from their social circle, except for their relations with medical specialists. Self control during pregnancy, thus, becomes an issue, reinforcing a wider concern with emotional control common in modern western societies.
\end{abstract}

Key Words: Pregnancy, Mass Media, Emotions. 
A gravidez enquanto processo que ocorre no corpo revela como este é cingido e vivenciado de acordo com significados $e$ práticas culturais - desde as noções sobre a concepção e a própria gestação às intervenções e cuidados com a gestante. Enquanto processo situado no corpo das mulheres, diz respeito às questões de gênero - o lugar social das mulheres, a importância da maternidade na construção de papéis e subjetividades femininas $e$ as relações de gênero na família. Enquanto processo que reproduz sujeitos, a gravidez põe em foco não apenas conceitos de pessoa, mas a constituição de laços familiares e a reprodução da sociedade de forma mais ampla que, no mundo ocidental moderno, tem sido alvo de saberes médicos e do desenvolvimento de novas tecnologias e de políticas públicas.

Neste trabalho, examino as representações em torno da gestação apresentadas na Revista da Gestante, da Online Editora, e voltada para o grande público. ${ }^{1}$ Em particular, analiso a forte presença das emoções como tema de várias matérias, caracterizando a gravidez como um estado emotivo. Argumento que o modo como as emoções figuram na revista ajuda a revelar como se pensa a gestante enquanto pessoa e sua relação com os outros. Trabalho a noção de pessoa enquanto categoria cultural que, no caso, articula tanto uma visão sobre o corpo como uma ideia de subjetividade, ambas culturalmente construídas.

Como contraponto a essas representações, apresento de forma breve dados de minha pesquisa de campo com gestantes de camadas médias, baseada tanto em entrevistas quanto no acompanhamento de um grupo de gestante no Rio de Janeiro em 2008. Embora a análise desse material tenha sido realizada em

1 Uma primeira versão deste trabalho foi apresentada no GT Subjetividade e emoções, na $32^{a}$ Reunião da ANPOCS, Caxambu-MG, 2008. Os dados resultam do projeto "A experiência da gravidez: corpo, subjetividade e parentesco" apoiado pelo Programa ProCiência da UERJ e pelo CNPq. Contei também com bolsa de iniciação científica do programa PIBIC/CNPQ/UERJ entre 2007 e 2008, tendo Tássia Raquel Gusmão como bolsista que participou da análise das revistas. Agradeço à leitura cuidadosa de Myriam Lins de Barros. 
Um estado emotivo: representação da gravidez na mídia

outro trabalho (Rezende 2009), pontuo neste artigo como a relação entre gravidez e emoção aparece para estas mulheres, de modo a comparar com as imagens veiculadas na revista em questão.

A Revista da Gestante começou a ser publicada a cada bimestre a partir de 2006. Tem como público alvo, segundo informações da editora, mulheres acima de 20 anos das classes A e $\mathrm{B}$, suas matérias voltam-se em geral às primíparas. Elegi para análise as reportagens dos números publicados em 2007 (ao todo, cinco revistas) além de dois suplementos especiais (Guia da gestante e Gravidez sem mistérios) veiculados com as revistas.

Ao propor estudar as representações sobre gravidez em uma revista, é preciso fazer comentários em torno do fato de ter um elemento da mídia como objeto de pesquisa. Primeiramente, parto do princípio que a revista deve ser tomada como um meio de comunicação, uma forma de comunicar imagens, ideias, valores, visões de mundo de um ou mais grupos sociais para outros. Não me ocuparei neste trabalho da recepção dessas noções, mas com sua construção, de forma a compreender quais representações sobre a gravidez circulam na mídia. Compartilho da postura já clássica de Umberto $\mathrm{Eco}$, em sua análise das histórias do Super-homem, que mais do que ver o personagem como meio de impor um modelo e desejos específicos à massa - o que seria uma interpretação "apocalíptica" da comunicação privilegia uma visão "integrada" dele como "reflexo de uma situação social, reafirmação periférica de um modelo geral" (Eco, 1979:263). Ou seja, acredito que as ideias veiculadas pela revista refletem visões de mundo mais amplas, com as quais as leitoras dialogam no momento de leitura.

Em segundo lugar, é importante destacar que, além de um elemento da mídia, a Revista da Gestante pode ser caracterizada como um gênero da literatura de auto-ajuda, que tem como traço principal, o discurso prescritivo, cujo maior objetivo é sugerir regras de conduta e dar conselhos. Como argumenta Rüdiger (1996:14), 
a literatura de auto-ajuda constitui uma das mediações através das quais as pessoas comuns procuram construir um eu de maneira reflexiva, gerenciar os recursos subjetivos $e$, desse modo, enfrentar os problemas colocados ao indivíduo pela modernidade.

Indo além, Salem (1992) destaca que há nessa literatura uma representação do sujeito dotado de força voluntária e do livre domínio de si, que formam o princípio, o meio e o fim almejado nos textos. Assim, analisar as representações de uma revista que se enquadra na literatura de auto-ajuda implica em lidar com essa visão específica do indivíduo, que, como veremos adiante, informa a figura da gestante nas reportagens examinadas.

A Revista da Gestante configura também um exemplo do que Condé (2007) denomina como a "felicidade mediada". A imprensa conselheira, da qual essa revista faz parte, seria, segundo o autor, não apenas um caso de literatura de auto-ajuda, mas também um discurso que toma o sentimento de felicidade como obrigatório, oferecendo meios de conquistá-lo. Portanto, na base dessa literatura está uma concepção de sujeito que, por meio da razão, pode alcançar um estado emocional específico. A ênfase na felicidade seria um aspecto especificamente moderno, reforçando a noção da "construção de si como tarefa infinita" (Bruckner, 2002:53).

Neste artigo, as emoções formam tanto o conteúdo específico das reportagens analisadas como também característica mais geral do gênero literário estudado. Para tanto, parto de uma abordagem antropológica das emoções, que as considera fenômenos culturalmente construídos. Mais ainda, estudar as emoções implica não apenas compreender a noção de pessoa em questão, como também tomá-la em relação com outras pessoas, com a ordem moral, com a organização social e política de modo amplo. Assim, a análise das emoções deve estar atenta ao contexto no qual são acionadas e em suas consequências, isto é, deve buscar uma visão pragmática, mais do que expressiva, 
Um estado emotivo: representação da gravidez na mídia

desses fenômenos (Abu-Lughod e Lutz, 1990). Embora não examine a recepção da revista e por meio dela os efeitos de seu discurso emotivo, este trabalho está centrado nos contextos discursivos nos quais as emoções aparecem - em relação a que temas e pessoas estão ligadas, como são explicadas e como devem ser tratadas.

Na primeira parte deste artigo faço uma breve revisão sobre maternidade, corpo e gravidez a partir do olhar das ciências sociais e as restantes contêm a análise empírica. Nestas, começo com uma caracterização geral da Revista da Gestante e das reportagens que discutem as emoções na gravidez. Em seguida, examino os sentimentos que mais aparecem nos artigos e seus significados, fazendo na seção posterior uma breve análise dos sentimentos que figuram nos dados da pesquisa de campo. $\mathrm{Na}$ parte final, destaco qual a concepção de pessoa que se desvela a partir do modo como as emoções figuram no material analisado.

\section{Maternidade, gravidez e corpo nas ciências sociais}

As sociedades ocidentais vivenciaram grandes transformações na família nos últimos séculos. Em seu estudo clássico, Áries (1981) discutiu como, passando de um modelo extenso para sua forma nuclear, a família foi se constituindo, a partir do século XVII, como base das trocas afetivas entre cônjuges e pais e filhos, e espaço privilegiado de educação das crianças. Nesse quadro, desenvolveu-se também uma nova concepção de maternidade - até mesmo uma "invenção da maternidade", segundo Giddens (1993) -, na qual as mães tornavam-se mais responsáveis pela criação e afeição dada aos filhos. Surgia então uma associação estreita entre maternidade e feminilidade enquanto "qualidades da personalidade" (Giddens, 1993:54).

A partir de meados do século $\mathrm{XX}$, novos processos afetaram a família e, com ela, as concepções e vivências da maternidade. Com maior formação escolar e profissional, as mulheres começaram a ocupar um espaço maior no mercado de trabalho e, de modo geral, na esfera pública. O desenvolvimento das novas 
tecnologias reprodutivas, em particular dos métodos contraceptivos, foi um elemento fundamental tanto para a redução da taxa de fecundidade quanto para a possibilidade de fazer da maternidade uma escolha baseada na reflexividade (Scavone, 2001). Se, na década de 50 na sociedade brasileira, a maternidade era um "destino inevitável" para as mulheres de camadas médias que se casavam (Almeida, 1987), suas filhas na década de 80 escolhiam ser mães, como fruto de um desejo subjetivo e não de uma trajetória a ser seguida automaticamente como fizera a geração mais velha.

Nas últimas décadas do século XX, a família sofreu novas transformações, pautadas principalmente pela valorização crescente da individualização de seus membros, cujos comportamentos orientam-se mais por motivações idiossincráticas do que por papéis sociais previamente estabelecidos. Aliada a isso, fortaleceu-se a ideia de que as relações conjugais devem se estabelecer e se manter em bases afetivas e de acordo com satisfação individual de cada cônjuge, modelo que Giddens (1991) chama de "relação pura". Esses novos valores morais explicam em grande medida um maior questionamento das relações de gênero na família, a maior ocorrência de divórcios e a grande diversidade de modelos familiares encontradas desde então.

Essas transformações mais gerais nas sociedades ocidentais modernas podem ser observadas também na sociedade brasileira. A busca da individualidade e de relações conjugais construídas sobre o afeto tornou-se um valor importante, principalmente nas camadas médias. Ainda assim, a constituição de família com a presença dos filhos permanece central para diversas camadas sociais, como mostram Luna (2007) e Araújo e Scalon (2005). A busca da realização profissional passou a ser uma fonte importante de felicidade para as mulheres pesquisadas, coexistindo, contudo, com a centralidade da maternidade. Ter filhos ocupa ainda um lugar significativo tanto nas trajetórias das mulheres quanto nas relações conjugais, como "algo que confere sentido à própria existência" (Araújo e Scalon, 2005:37). Apesar da 
Um estado emotivo: representação da gravidez na mídia

crescente participação dos homens nas tarefas domésticas, ainda recaem sobre as mulheres os maiores encargos com o cuidado da casa $e$ dos filhos que, aliados ao trabalho, resultam em uma percepção de maior pressão sobre elas.

Nesse contexto, pode-se pensar na gravidez do primeiro filho como uma fase em que as tensões em torno da individualização ficam ainda mais realçadas, seja na relação da gestante com a rede de parentesco mais ampla, seja no próprio processo de construção de uma subjetividade feminina diante da conciliação da futura maternidade com outros papéis sociais. $\mathrm{Na}$ relação com as famílias de origem, podemos encontrar movimentos de evitação e isolamento do casal (Salem, 2007), cuja ênfase na vivência emocional e subjetiva intensa da gravidez do primeiro filho causava grandes alterações na rede de relações familiares e de amigos. De outro modo, a gravidez entre adolescentes tem sido uma forma de conquista de autonomia dos jovens em relação a seus pais (Brandão, 2005, Dias, 2005). Mas vemos também relações de participação $e$ apoios material $e$ emotivo (Rezende 2009). ${ }^{2}$

Com relação à subjetividade feminina, se a gravidez pode ser vista como estágio para ou da maternidade (LoBianco, 1985), esta continua central nas trajetórias femininas, mesmo com as mudanças nos papéis de gênero na família e na esfera pública. Como enfatizam algumas autoras (Strathern, 1995, Ragoné, 1997, Luna 2007), o recurso às novas tecnologias reprodutivas é motivado muitas vezes por papéis de gênero e feminilidades muitas vezes orientadas por valores tradicionais. Nesses casos, o que encontramos frequentemente são tensões e conflitos entre uma desestabilização de papéis de gênero e o peso dado à maternidade (LoBianco, 1985), entre o desejo de ser mãe e a separação dos vários elementos - social e biológico, agora

\footnotetext{
2 Nos Estados Unidos, Rapp (1998) destaca o apoio da família nas decisões de
} ter um bebê cujo diagnóstico de amniosintese tenha apontado anomalias. 
subdividido pelas etapas de concepção e gestação - que constituíram durante muito tempo o significado de maternidade.

Se a gravidez coloca tensões tanto para a individualidade da gestante quanto para suas relações familiares, há outras dimensões especificamente corporais que também incidem sobre sua subjetividade. Essa interseção entre os planos biológico, psicológico e sociológico do corpo já é enfatizada desde o ensaio clássico de Marcel Mauss (1974), que o tomou como objeto legítimo das ciências sociais. Nas sociedades ocidentais modernas, o modo como o corpo articula as relações entre o indivíduo e a sociedade, e entre a natureza e a cultura, ganha matizes muito particulares.

Nessas sociedades, torna-se central a questão do controle exercido sobre o corpo, tanto pelo próprio indivíduo quanto pelo grupo social mais amplo. As obras de Foucault $(1977,1997)$ e Elias (1990) são análises clássicas desse tema. Para Foucault, o corpo torna-se alvo de novas formas de poder que o disciplinam sob todos os aspectos. Segundo ele, em torno do corpo desenvolvemse saberes - médicos, psicológicos, jurídicos, demográficos - que atravessam vários campos de poder, sendo sua medicalização um dos processos mais significativos. Desenvolve-se também uma relação estreita entre corpo e subjetividade, como também se estabelece com ele uma relação de auto-escrutínio, de inquirir e revelar sempre (Foucault 1997).

De um modo distinto, mas também pensando a junção de mudanças macro e microssociais, a obra clássica de Elias (1990) toma o desenvolvimento do autocontrole emotivo e corporal como um elemento significativo do "processo civilizador". Este é resultado de uma crescente especialização funcional que aumenta a interdependência entre as pessoas $e$ da centralização $e$ monopólio do uso da força pelo Estado, transformações que se consolidam principalmente no século XIX. Para o indivíduo, ambas exigem um controle de suas emoções e de seu corpo cada vez mais amplo - todos os afetos devem ser moderados, em todos os momentos, auto-regulação que é internalizada pela socialização 
Um estado emotivo: representação da gravidez na mídia

desde a infância e que desloca para o interior de cada sujeito os embates entre a necessidade do controle e a expressão de seus afetos.

Nas análises mais recentes sobre o corpo na modernidade tardia (Featherstone 1991, Giddens 1991, Ortega 2006), debate-se como a tensão entre indivíduo e sociedade reflete-se no corpo através do conflito entre a busca de uma identidade e imagem corporal singulares, que são ao mesmo tempo modeladas socialmente, e o pertencimento $e$ a adesão a determinados grupos sociais e seus valores. Em ambas as situações, está em foco o controle exercido sobre o corpo pelo sujeito e por instâncias externas. Nesse processo, as técnicas de intervenção disciplinadora sobre o corpo - dietas, exercícios, cirurgias, tratamentos médicos, etc. - põem em xeque o que nele é natural e o que é cultural/construído.

Para as mulheres, essas questões adquirem uma relevância particular, pois o cuidado do corpo é um elemento central na construção de uma visão tradicional de feminilidade. Além disso, na sociedade ocidental moderna, seus corpos são percebidos como sendo mais marcados pela natureza (Juer, 2007, Ortner, 1979), principalmente por sua função reprodutora, e suas subjetividades mais afeitas à emotividade (Lutz, 1990). Desse modo, as intervenções sobre seus corpos, por exemplo, exercícios e dietas para não engordar, tornam-se formas de exercer um autocontrole que, caso falhe, pode demonstrar uma "fraqueza" (Melo, 2004) que se traduziria também como falta de empenho racional.

$\mathrm{Na}$ gravidez, esses problemas tendem a se aguçar com a transformação do corpo. A disciplina sobre o corpo através de dietas e exercícios se coloca tanto em nome da saúde da gestante $e$ do feto quanto por razões estéticas, com a preocupação frequente de evitar mudanças corporais permanentes. É importante ressaltar que, em termos de sociedade brasileira, esses são receios mais comuns nas camadas médias, pois no estudo de Paim (1998) sobre mulheres de camadas populares no sul do país, 
as estrias e cicatrizes da gravidez são apresentadas enquanto formas de demonstrar o novo status de mulher adulta. Mesmo quando as marcas são indesejadas, o recurso à cirurgia plástica é comum para "corrigi-las", principalmente entre mulheres de camadas médias que têm não apenas o poder aquisitivo para buscá-la, como também um ideal de corpo magro e rijo (Edmonds, 2002).

Outro aspecto do controle sobre o corpo no estudo da gravidez é a medicalização da concepção e da gestação. ${ }^{3}$ Com as novas tecnologias reprodutivas, a concepção passa a ser um processo cada vez mais sob controle externo, atravessado por interesses comerciais e aspectos jurídicos, podendo mesmo se tornar público quando acontece fora do corpo (Franklin 1997). Com a segmentação cada vez maior de saberes e esferas de ação, agora, concepção e gestação são etapas que podem ser fragmentadas - a primeira pode acontecer fora do corpo e o embrião que resulta pode não ter elo genético com o corpo que o gesta. A gestação também passa a ser uma condição médica, controlada por um saber especializado e cuidada através de consultas médicas e vários exames para monitorar a saúde do feto e da gestante Ao contrário de outras sociedades e épocas, a gravidez deixa de ser vista, em larga medida, como um processo "natural" do corpo para ser um que necessita de intervenção $e$ controle médicos. Não à toa, o parto foi uma das últimas esferas a ser medicalizada e transportada para o hospital em fins do século XIX e início do século XX (Rohden, 2006, Tornquist, 2004), deslocando um saber que até então era essencialmente feminino para o domínio de médicos, em sua maioria homens.

Se a discussão sobre o controle do corpo está diretamente relacionada às concepções de sujeito, no caso da gravidez essa questão ganha aspectos singulares em função da presença do feto

3 Entretanto, o tipo e o grau de controle exercido por meio das tecnologias médicas variam mesmo dentro das sociedades ocidentais (Mitchell e Georges, 1998; Chazan, 2005). 
Um estado emotivo: representação da gravidez na mídia

no corpo feminino. Para a subjetividade feminina, a gestação provocaria a antítese da individualidade, uma vez que divide o corpo da mulher em dois (Martin, 1998). Nessa dualidade, a maior ou menor atenção dada à gestante vis a vis o feto é variável não apenas entre culturas como também entre segmentos sociais de uma mesma sociedade. A gestante nas sociedades ocidentais é cercada de cuidados e atenções especiais, havendo recentemente uma valorização intensa da experiência corporal da gestação (Vargas e Russo, 2005). Mesmo assim, há diferenças significativas no modo como a gestante se vê, como aponta Lo Bianco (1985), comparando no Rio Janeiro um grupo de camadas médias com outro de camadas populares. Entre as primeiras, a gravidez é vivida como um "estágio da maternidade"; para as segundas, ela seria um "estágio para a maternidade". Enquanto estas se preocupam principalmente com a vida após o nascimento do bebê, aquelas elaboram os sentimentos em relação ao feto, tratando-o desde a gestação como um ser com vontade própria dentro dos parâmetros do que pensam ser a relação mãe-filho.

Assim, nesta breve revisão bibliográfica, destaca-se o tema central do controle em torno do corpo nas sociedades ocidentais modernas. Exercido de fora - através de instituições e campos de conhecimento - e de dentro - por um sujeito capaz de se autocontrolar constantemente, esse controle torna-se uma questão ainda mais aguda na gravidez, quando o corpo feminino carrega um feto. Além dos cuidados corporais por motivos estéticos e da medicalização da gestação, o controle se apresenta na tensão entre uma maior ou menor individualização, colocada tanto no modo como a gestante constrói sua subjetividade - $e$ o peso dado à maternidade em relação a outros papéis - como na forma como lida com os outros, em particular com a família. Como veremos, essas são as questões mais tratadas na Revista da Gestante e, nela, as emoções desempenham um papel desestabilizador. 
Claudia Barcellos Rezende

\section{Um estado naturalmente emotivo}

Para compreender como as emoções são tratadas nas matérias, é preciso antes descrever brevemente a Revista da Gestante. A primeira parte, e a mais curta, consiste de seção de cartas dirigidas a vários especialistas (ginecologista, obstetra, dermatologista, psicólogo e pediatra), e seção com lançamentos para gestante e bebê (produtos, livros e sites informativos na internet); a segunda parte, a maior delas, com matérias sobre gravidez; a terceira parte sobre pós-parto e a quarta parte sobre o bebê. Para este trabalho, analisamos apenas os textos da parte sobre gestação, a mais significativa da revista.

Nesta seção, há em geral matérias sobre cuidados corporais (em torno da nutrição, da estética e do bem-estar), moda para gestantes, informações de cunho médico (sobre as fases da gestação, tipos de parto e de anestesia, exames do pré-natal) e comportamento. Essa última categoria engloba tanto reportagens que discutem, por exemplo, a conciliação entre gravidez $e$ trabalho e o recurso a doulas - profissionais que acompanham a gestante no parto e pós-parto - como as emoções surgidas nesse período. Nas cinco revistas analisadas, encontramos duas reportagens voltadas especificamente às emoções - "Você tem medo de que?" (ano 2, n 16) e "À flor da pele" (ano 2, no 12), embora muitas outras discutam o tema articulado a outras questões, por exemplo, a conciliação entre maternidade e vida profissional ou então as várias fases da gestação.

A referência mais frequente às emoções nas revistas é a "maior sensibilidade" ou mesmo "instabilidade emocional" vivida pela mulher, principalmente nos primeiros meses de gestação. Em grande parte atribuída às mudanças hormonais, essa instabilidade, considerada até um sintoma, é vista como normal, dentro de certos limites. Dessa alteração emocional podem surgir sentimentos variados - ansiedade, agressividade, medo, culpa - e agrega-se uma emotividade maior às reações da mulher no cotidiano, como chorar com "um simples abraço ou uma cena 
Um estado emotivo: representação da gravidez na mídia

mais bonita na novela". De um modo geral, as matérias fazem várias recomendações em busca de um maior equilíbrio emocional. Nos casos mais graves, deve-se conversar com o obstetra para que encaminhe a gestante para um especialista psicólogo ou psiquiatra.

$\mathrm{O}$ segundo tema das reportagens que geralmente suscita menção às emoções é o desenvolvimento do bebê $\hat{e}^{4} e$ principalmente o parto. Ansiedade e medo são os sentimentos mais citados e surgem das preocupações com a saúde e formação do bebê e com a aproximação do momento do parto. Nessa última fase da gestação, essas emoções resultariam de preocupações com o parto em si - saber identificar o trabalho de parto, a presença da dor, a necessidade de intervenção cirúrgica, entre outros - e também com o pós-parto, sendo a amamentação mencionada como motivo de receio. Embora esses sentimentos também sejam considerados normais, recomenda-se que a gestante busque se tranquilizar, informando-se com apoio de doulas e grupos de gestantes.

Os outros contextos de reportagens nos quais se fala das emoções são menos frequentes nas revistas, embora cada vez que esses assuntos aparecem haja menção a sentimentos. São eles a relação da mulher com seu trabalho e a vida sexual do casal durante a gestação, ambas esferas da vida que produzem sentimentos também considerados normais. O primeiro seria fonte de ansiedade, insegurança e stress, tanto pelo receio de queda do desempenho e perda de promoções e até mesmo do emprego, quanto pela antecipação da conciliação, após o nascimento do bebê, entre a maternidade e a vida profissional. Sugere-se novamente informar-se sobre os direitos, relaxar a autocobrança e buscar formas de compensar os efeitos de possíveis incômodos no trabalho. De forma semelhante, manter a vida sexual do casal também geraria ansiedade e medo, tanto por receios que o bebê

4 Nas revistas, o termo "feto" - o termo médico mais comum - aparece bem menos do que "bebê", mesmo quando se referem a ele durante a gestação. 
sofra algo durante o ato sexual, como pelas dúvidas sobre a atração sexual que o parceiro sente pelo corpo grávido. Como nos outros temas, os artigos indicam a conversa com o médico e com o parceiro como modo de dissipar esses sentimentos e fortalecer a união do casal.

De modo geral, a gravidez é tratada como uma fase da vida pontuada naturalmente por muitas emoções. O estado emotivo é entendido como natural em dois sentidos. Em termos biológicos, as mudanças hormonais na gravidez são vistas como uma verdadeira "revolução interna" que tem efeitos diretos sobre as emoções. Essa visão é consoante com noções presentes no senso comum e também no saber médico (Juer 2007, Martin 2006) que atribuem aos hormônios a responsabilidade por certos estados emocionais, principalmente nas mulheres. A maior emotividade na gestação também é tida como natural no sentido de um padrão esperado, que seria comum a uma experiência desconhecida (lembro que as reportagens dirigem-se especialmente às primíparas) que envolve mudanças corporais, subjetivas e sociais.

Apesar da naturalidade das emoções, todas as matérias recomendam a busca de equilíbrio emocional e de tranquilidade. Ou seja, embora seja normal sentir medo, ansiedade, etc., é melhor não senti-los. Nesse aspecto, encontramos a questão já discutida na revisão bibliográfica em torno da necessidade de auto-controle emocional constante. Mais do que isso, o controle das emoções deve caminhar em uma direção específica, que implica buscar não apenas a estabilidade emocional, mas também os sentimentos de felicidade e alegria. Assim, a maior emotividade da gestante poderia produzir culpa e perplexidade diante de reações de tristeza e choro que "não condizem com a alegria de gerar um nenê" ("À flor da pele", ano 2, n 12, p.17). Portanto, todos os esforços da revista se dirigem a ajudar a grávida com "dicas valiosas para uma gestação tranquila, saudável e feliz" (manchete do número especial, ano $\left.2, n^{\circ} 7\right)$.

A conquista do equilíbrio emocional implica buscar outras pessoas, mesmo que ler a revista seja um passo intermediário no 
Um estado emotivo: representação da gravidez na mídia

processo. Os outros ajudam principalmente com informação $e$ diálogo. Nesse sentido, a figura que oferece ambos é o obstetra, especialista que não apenas detém o conhecimento que traz segurança, mas que pode ouvir as preocupações e medos da gestante. Ele é o mais citado na revista como alguém que sempre pode ajudar a gestante, mesmo quando o assunto é a vida sexual do casal, e que pode encaminhá-la para outros especialistas, se necessário. O parceiro é outra pessoa significativa para conversar e dialogar, além de poder dar carinho e apoio à grávida. Há também as figuras das doulas, cujo propósito seria dar segurança à grávida principalmente no parto e pós-parto, e dos grupos de gestantes, que reúnem outras gestantes que compartilham seus receios e assim acalmá-los. Em algumas situações, como na relação com o trabalho, a família e os amigos aparecem como fonte de apoio e carinho, mas em outras, ao emitirem comentários e opiniões tidas pela revista como "tolices", provocam justamente a ansiedade e o medo tão problemáticos.

\section{O predomínio do medo e da ansiedade}

A alegria $e$ a felicidade devem coroar a gravidez $e$ a maternidade, vistas como um "dom" que as mulheres têm. Entretanto, os sentimentos mais discutidos nas reportagens são o medo $e$ a ansiedade, presentes frequentemente nos títulos das reportagens. Em alguns casos, fala-se também em tristeza, que seria decorrente das transformações hormonais, e culpa, resultado da presença desses outros sentimentos que ofuscam a felicidade esperada. Em parte, como disse antes, a presença mais forte das emoções na gravidez é atribuída às mudanças hormonais, mas há também fatores referentes ao modo de lidar com uma experiência que seria nova para as leitoras..

Embora sejam sentimentos distintos, medo e ansiedade aparecem quase sempre em conjunto, em alguns casos acrescidos da angústia, e pontuam todos os aspectos da gravidez fisiológico, subjetivo e social. As causas do medo são, em grande 
parte, associadas à saúde do bebê e da gestante, sendo o parto uma fonte importante de medo e ansiedade. Fala-se também de medos em relação ao futuro papel de mãe e também, como já apresentei, em relação à vida sexual do casal e à conciliação da gravidez e suas possíveis restrições ao desempenho profissional.

No artigo "Você tem medo de que?" (ano 2, no 16), a ocorrência dessas emoções, vista como normal, é atribuída a "sensações jamais vividas antes". Como explica uma psicóloga citada, "a mulher passa por inúmeras mudanças, como a da sua imagem corporal e da sua relação com o companheiro e com o feto". Segundo a matéria, cada fase da gestação pode provocar medos distintos. Nos primeiros meses, pode surgir "angústia" em torno da possibilidade de perder o bebê. Nos meses seguintes, pode aparecer o receio com problemas de formação e doenças do bebê. No estágio final, é comum ter medo do parto, da anestesia, dos cuidados com o bebê no pós-parto.

De modo geral, o sentimento de ansiedade na gestação remete à sensação de estar vivendo "uma situação nova $e$ singular", de não saber da capacidade "de dar conta do que está por vir", de querer prever como será o bebê, de querer saber como vai ser o parto, ou seja, de enfrentar o desconhecido. A ansiedade em torno da maternidade por vir vai além da relação de mãe e filho, perpassando também a relação de casamento e as relações de trabalho. Ou seja, a repetida ênfase na ansiedade como sentimento predominante na gravidez revela o desconforto com a falta de controle em torno de uma experiência que produzirá mudanças em todos os outros aspectos da vida da mulher.

O sentimento de ansiedade nesse caso aponta de forma explícita para como a falta de controle na gravidez, de forma ampla, pode ser vivida como problema. Não é apenas a falta de controle sobre o corpo, tanto em termos de sua aparência quanto de sua saúde, ambas questões caras nas sociedades ocidentais modernas. Há também dúvidas em relação à capacidade de desempenhar não apenas um novo papel, mas um que, apesar 
Um estado emotivo: representação da gravidez na mídia

das transformações nas relações de gênero das últimas décadas, ainda tem um significado marcante para a definição de feminilidade. Na verdade, é justamente porque as relações de gênero mudaram e o trabalho passou a ser fonte de identificação para muitas mulheres que o papel de mãe, mesmo que significativo, não seja dado nem em termos do desejo, nem da percepção de capacidade para desempenhá-lo.

Além disso, mesmo a relação que produz o filho - que nos artigos da revista é sempre desejado -, não parece ser fonte de segurança. Se, como Schneider (1968) analisou na década de 60, a relação sexual torna-se símbolo do amor que une o casal, recentemente esse amor parece cada vez mais líquido, nos termos de Baumann (2003). Assim, o projeto de formar família, longe de produzir um sentimento de estabilidade e segurança, gera ao contrário ansiedade, pois a vida sexual do casal, tão simbolicamente importante, fica ameaçada pelas transformações do corpo grávido - as que ocorrem durante a gravidez e as que podem permanecer após o parto. Daí a considerável atenção dispensada aos cuidados corporais estéticos.

Por sua vez, o sentimento de medo surge da possibilidade de que essa experiência desconhecida e que terá que ser enfrentada seja problemática, difícil, e dolorosa. Também em termos emocionais, buscam-se caminhos para que a gestação não se transforme em uma experiência dolorosa, seja em termos de problemas de saúde do bebê ou da gestante, seja em termos dos efeitos da gravidez no conjunto de relações da mulher.

O sentido da emoção do medo aqui articula a questão do controle à evitação da dor em um sentido amplo. Esse seria um traço das sociedades ocidentais modernas, nas quais a dor deixa de ser um fato existencial para tornar-se um dado fisiológico, possivel de ser medicalizado (Ortega 2006). Assim, a dor é uma experiência a ser evitada e controlada a qualquer custo $e$, com os avanços da medicina, torna-se possível de fato amenizar e até anular a dor física. Mesmo o sentimento da dor também parece ser um tanto anacrônico. Como já disse, a felicidade é imperativa 
nos tempos modernos $e$ a dor $e$ a tristeza não são vistos como sentimentos que podem enriquecer a subjetividade, como em outros tempos (Sontag 1984).

Assim, a ansiedade e o medo são sentimentos que devem ser atenuados não apenas para o bem estar da gestante como também do bebê. Em apenas uma única ocasião, a perda do auto-controle emotivo é vista como legítima. Em um artigo sobre enjôos, embora os hormônios sejam vistos como tendo um papel explicativo, metade do texto é dedicada aos aspectos psicológicos que estariam presentes como suas causas, opinião que seria unânime entre os especialistas. Segundo a psicóloga citada, é comum que a mulher grávida sinta ambivalência em relação à gestação, desejando-a e rejeitando-a ao mesmo tempo. Essa ambiguidade resulta de uma mudança que "envolve perdas $e$ ganhos" e de que "a mulher se sinta confusa desejando muito ter o filho e, ao mesmo tempo, querendo manter tudo como era antes, sob seu controle" (meu grifo). Como a gravidez é socialmente considerada "uma dádiva de Deus", a mulher nem teria consciência do sentimento de rejeição e sentiria culpa ao se dar conta dele. Essa rejeição pode então ser externada no corpo, de forma psicossomática, como nos enjôos. Embora a matéria enfatize que há razões fisiológicas para esse sintoma, ele pode ser visto como "a soma do fisiológico e do psicológico".

Neste artigo, então, as emoções se originam não dos hormônios, mas da relação da mulher com o papel de mãe. $\mathrm{O}$ corpo aqui se torna meio de expressão de sentimentos de rejeição que seriam difíceis de serem percebidos ou encarados em uma situação social de valorização da maternidade. A falta de autocontrole emocional, neste artigo, é uma perda legitimamente sentida, ainda que seja um problema a ser sanado. Assim, a perda de autocontrole causada por outra pessoa - no caso o filho em gestação - é aceita, ainda que também tenha sido desejada. Daí a aceitação dos sentimentos de ambivalência e rejeição, que devem ser "assumidos". 
Um estado emotivo: representação da gravidez na mídia

Aqui também se explicita a dimensão moral do problema emotivo - a presença de sentimentos de rejeição em algum grau de um papel e modelo de feminilidade socialmente valorizado. Essa moralidade tem um embasamento religioso ambíguo - ao mesmo tempo em que a maternidade é uma dádiva de Deus, rejeitar parcialmente esse dom não é pecado (lembro que a recusa completa do dom seria não engravidar ou então abortar). Apesar dessa ambiguidade, a conotação moral do problema está também na ideia de que, apesar de possíveis sentimentos de perda com a gravidez, o desejo de ter filhos não está em questão. Ou seja, querer ter filhos é não apenas a norma, mas também um desejo "natural" - no sentido de ser normal e quiçá também da ordem da natureza.

O principal meio de controlar esses sentimentos de ansiedade, medo e rejeição é a conversa, tanto para se expressar como para se informar, principalmente com o médico obstetra. Em nenhum momento das reportagens coloca-se em questão a possibilidade de que a própria relação com o médico também suscite ansiedade. Ao contrário, todas as outras relações, inclusive a com o companheiro, podem gerar ansiedade e produzir temores, menos aquela estabelecida com o médico. Do mesmo modo, presume-se que os exames do pré-natal, principalmente a ultrassonografia, bem como a própria ideia de informação contribuam para dissipar esses sentimentos, ao invés do contrário, como mostrarei adiante.

Nesse sentido, nas reportagens dessa revista, o saber médico - expresso tanto pela figura do médico como pelas técnicas dos exames - é inquestionável e superior a outros, como as informações e opiniões de amigos e parentes que são desqualificadas como "tolices", reforçando um movimento no qual a medicalização revela-se fonte de poder e reestruturação de relações. Como já disse, a gestação foi uma das últimas esferas a ser medicalizada e nesse processo, o saber essencialmente feminino foi deslocado e mesmo reprimido. O cuidado da 
gestação e o parto passam a excluir a participação da família, cujo papel deve se restringir a dar apoio emocional à gestante.

A visão que a conversa e o diálogo são meios de controlar essas emoções é coerente com uma percepção psicologizada do indivíduo. Como explica Salem, o "eu" torna-se o foco de introspecção comprometida com "a exigência de um constante trabalho sobre si mesmo com vistas ao aperfeiçoamento" (2007:151). Não somente parte-se do pressuposto de que as emoções são estados internos ao indivíduo, mas que também eles devem ser externados e elaborados verbalmente. Novamente, encontra-se aqui a injunção à confissão discutida por Foucault (1997), que embora se tornando obrigatória, é vista como libertadora. Como destaca Salem (2007:152), "a compulsão a "vasculhar-se" vincula-se à compulsão a "abrir-se" - seja no santuário do espaço analítico, seja na relação de pares", de forma que a postura de uma reflexividade introspectiva acaba pautandose em uma prática social compartilhada.

\section{Ansiedade e medo em um grupo de gestantes}

A estreita articulação entre gravidez e emoção permeia não apenas as representações veiculadas na Revista da Gestante, mas também as experiências das gestantes que pesquisei no Rio de Janeiro. Para Mariana ${ }^{5}$, que estava com seis meses de gestação quando entrevistada, "resumo de gestação, palavra que resume tudo é medo". O medo dependia do momento. No início foi o medo de perder o neném. Depois veio o medo de fazer exames e descobrir algum problema com o bebê. Naquele momento, seu medo maior era do neném ter algum problema de saúde ao nascer e principalmente como vai ser ter um filho para criar. "Como vai ser cuidar? Você vai dar conta? Você vai ter a paciência que precisa?", dizia Mariana, que ainda falava no medo de perder seu lugar na relação com o marido e com a família.

\footnotetext{
5 Nome fictício.
} 
Um estado emotivo: representação da gravidez na mídia

A fala de Mariana resume também temas e sentimentos que apareceram ao longo dos encontros do grupo de gestante que presenciei. Em todas as reuniões, que aconteciam duas vezes por semana e eram coordenadas por uma psicóloga, havia referência aos medos das gestantes, bem como a um estado de ansiedade mais generalizado. Eram emoções recorrentes e dominantes, apenas uma vez apareceu o sentimento da felicidade, quando, em uma dinâmica de apresentação, todas disseram se sentir felizes com a gravidez.

A ansiedade aparecia como uma emoção mais difusa que surgia do desconhecimento sobre as mudanças produzidas pela gravidez em cada uma - principalmente o que seriam incômodos mais comuns no final da gestação. Para algumas, fazer exames gerava ansiedade sobre o resultado e a possibilidade de o bebê ter algum problema de saúde. Não saber como seria o parto - desde o reconhecimento dos primeiros sinais do trabalho de parto até o pós-parto - era outra fonte de ansiedade. Era esse sentimento que justificava a busca pelo grupo de gestante, pois as trocas de experiência com outras gestantes e as técnicas da ioga ajudariam a diminuir tal emoção.

As referências ao medo eram mais específicas. Falavam no medo de perder o neném no início da gestação e também no parto, no medo do parto normal - das dores do trabalho de parto, do corte na hora da expulsão, do uso de fórceps, no medo do parto cesárea -, da reação à anestesia, de algum imprevisto, do pós-operatório, no medo da amamentação - da dor de amamentar - e no medo de o marido perder o interesse sexual na mulher após o parto, em função de o corpo estar "fora de forma". Havia ainda medos mais pessoais, como o de uma gestante que tinha medo de ficar calma demais na hora do parto e não conseguir agir, ou de outra que teve medo de perder a avó, que adoeceu ao final da sua gestação.

No grupo de gestantes, assim como nas reportagens analisadas, a atenção era dirigida principalmente às sensações $e$ emoções das grávidas, $e$ as relações com o marido e a família 
durante a gravidez não foram alvo de discussão. $\mathrm{O}$ marido figurava principalmente como companheiro nas consultas médicas, nos exames, na compra de mobília e acessórios para o bebê, cuja participação ou interferência geralmente não era comentada, mas vista como dada. Apenas em um encontro surgiu a preocupação com a relação com o marido, que poderia se desinteressar da mulher em função de suas mudanças corporais. A sexualidade na gravidez era um dos possíveis temas de discussão apresentados pela coordenadora, mas não foi debatido em nenhum dos encontros que acompanhei. A família aparecia principalmente como forma de apoio logístico e material, através da ajuda com a compra do enxoval e mobília para bebê, e a figura da mãe era referência de informações e experiência de gravidez e parto. Mesmo a relação com o bebê aparecia muito pouco, salvo o fato de já ser sempre nomeado e às vezes ser visto como manifestando seus desejos ou insatisfações.

A relação com o médico foi bastante comentada e discutida e produzia ansiedade para muitas gestantes, mostrando uma visão distinta daquela afirmada na Revista da Gestante. A maioria delas havia trocado recentemente de médico, pois seus ginecologistas anteriores não tinham convênio com seus planos de saúde. Para muitas, a troca era vista como uma perda, pois com o antigo médico existia uma intimidade e uma confiança que ainda estavam sendo construídas com novo obstetra. A postura do médico em relação ao parto - se era favorável ao parto normal ou à cesárea - era uma preocupação para aquelas que desejavam ter parto normal. De modo geral, discutiam-se as informações passadas pelos médicos e falava-se bastante no que era possível negociar com o médico - escolha de forma de parto e de procedimentos a ser realizados.

Portanto, a relação com os médicos estava longe de gerar um sentimento de confiança e segurança nas gestantes. A busca por informações, em geral na internet $e$ em livros - nenhuma das gestantes lia a Revista da Gestante - era uma atividade complementar, mas que para algumas gerava ansiedade ao invés 
Um estado emotivo: representação da gravidez na mídia

de acalmar. A psicóloga, coordenadora do grupo, era a especialista respeitada, que explicava e informava de modo afetuoso. Assim, o grupo de gestantes e a família, a mãe em particular, eram os interlocutores responsáveis para diminuir o sentimento de ansiedade que todas expressavam.

\section{Considerações finais}

Encontramos na Revista da Gestante algumas concepções do imaginário ocidental sobre pessoa - a relação entre corpo $e$ emoção, bem como sobre gravidez e maternidade, analisadas aqui através da recorrência dos sentimentos de ansiedade e medo. $\mathrm{Na}$ medida em que essas emoções também aparecem no grupo de gestantes que pesquisei, podemos pensar a revista como um meio de veiculação de ideias e valores encontrados de forma mais ampla na sociedade.

No grupo de gestantes, ansiedade e medo remetem principalmente a uma relação "desnaturalizada" com a maternidade. Além de por em questão o controle do corpo, gestação coloca em foco principalmente a relação com a vida de forma ampla e com a conciliação entre o futuro papel de mãe e os outros já desempenhados pela gestante. Na pesquisa de campo, ter filhos era um desejo de todas as mulheres estudadas, mas o lugar da maternidade diante da relação conjugal, do trabalho e da própria autonomia individual não era claro. Não à toa, discutiu-se pouco essas relações tal como se apresentavam durante a gravidez. Estas não eram preocupações daquele momento, mas sim do futuro no pós-parto, daí o sentimento de ansiedade que fala de um receio com o que está por vir. Nesse sentido, a gravidez faria a gestante perder o controle de "tudo", tendo que contar com médicos que também não geravam segurança, produzindo, portanto, o sentimento de ansiedade que tanto permeia os encontros do grupo de gestante e também os artigos da revista. 
Na Revista da Gestante, o tema do controle de si desponta como a grande questão tratada nas reportagens analisadas, explicando a recorrência dos sentimentos de ansiedade e medo. Em primeiro lugar, o controle do corpo estaria afetado pelas transformações fisiológicas e orgânicas desconhecidas para a gestante. Em particular, a produção dos hormônios pelo corpo é vista como fator de desestabilização, não sendo, no geral, influenciada pela subjetividade da gestante. Ao mesmo tempo, é um corpo que precisa ser cuidado e controlado, como na necessidade de equilibrar possíveis desequilibrios hormonais.

Em segundo lugar, altera-se também o controle das emoções. No caso da gestação, os hormônios produzem mudanças emocionais, embora elas também surjam da relação da mulher grávida com outras pessoas e com valores, expectativas $e$ papéis sociais. Assim, as emoções são ao mesmo tempo particulares a cada pessoa e comum em função de sua base biológica. Nesse sentido, embora as experiências sejam variadas, a gestação é tratada de forma padronizada como um estado mais emotivo, potencializando ainda mais uma associação já recorrente das mulheres às emoções (Lutz, 1988 e 1990).

Nesse sentido, a Revista da Gestante, como exemplo de literatura de auto-ajuda, enfatiza os meios de manter ou recuperar o controle de si, considerado condição ideal por excelência. $\mathrm{Na}$ maioria das reportagens, a expressão dos sentimentos via conversa torna-se uma forma de autocontrole. A expressão através da conversa e do diálogo dá vazão, de forma adequada, aos sentimentos enquanto realidade interna ao indivíduo que, entretanto, precisam ser externadas sob risco de causar-lhe mais problemas. Embora haja momentos nas reportagens em que as expectativas sociais tornam-se formas de controle das emoções, o autocontrole não teria uma origem social ou cultural e seria basicamente um meio de gestão de si que promove o bem estar.

O que é marcante na Revista da Gestante, mais do que nos dados da pesquisa de campo, é a visão da gestante como indivíduo autônomo, cujas relações ficam em segundo plano, 
Um estado emotivo: representação da gravidez na mídia

consonante mais uma vez com a tônica da literatura de autoajuda. Na maioria das relações discutidas existe a percepção de fragilidade do vínculo - o parceiro cujo apoio deve ser requisitado e cujo interesse sexual deve ser mantido; os laços de trabalho que sofrem com as mudanças de desempenho profissional da gestante; a família e os amigos que podem dar carinho, mas que também trazem insegurança com suas opiniões infundadas. A relação com o bebê na fase da gestação é tratada unicamente em termos da ansiedade da gestante em relação a sua saúde aos cuidados após o parto. Nesse quadro, ao contrário das gestantes pesquisadas, a relação com o médico é a única vista como fonte de segurança $e$ auxílio para recuperação do autocontrole, pois está embasada no saber inquestionável da medicina. Nesse sentido, a revista reforça o poder do saber médico com uma visão medicalizada do corpo e do sujeito existente, de forma mais ampla, nas sociedades ocidentais modernas.

Assim, a gravidez desponta, nas reportagens analisadas, como um processo que implica, basicamente, a gestante consigo mesma. Apesar de um processo corporal que é desencadeado pelo ato sexual enquanto relação social (Schneider, 1968), que traz em si o desenvolvimento de um novo ser e que implica na construção de uma nova família, esses laços sociais ficam ofuscados por uma visão da gestante enquanto sujeito autônomo em busca da recuperação e da manutenção do seu autocontrole.

\section{Referências bibliográficas}

ABU-LUGHOD, Lila e LUTZ, Catherine. Introduction. In: LUTZ, Catherine e ABU-LUGHOD, Lila. (orgs.) Language and the politics of emotion. Cambridge, Cambridge University Press, 1990, pp.1-23.

AlmEIDA, Maria Isabel Mendes de. Maternidade: um destino inevitável?. Rio de Janeiro, Campus, 1987.

ARAúJO, Clara e SCALON, Celi. Percepções e atitudes de mulheres e homens sobre a conciliação entre família e trabalho pago no Brasil. 
Claudia Barcellos Rezende

In: ARAÚJO, Clara e SCALON, Celi. (orgs.) Gênero, família e trabalho no Brasil. Rio de Janeiro, Editora FGV, 2005, pp.17-77.

ARIÈS, Philippe. História social da criança e da família. Rio de Janeiro, Zahar, 1981.

Bauman, Zygmunt. Amor Líquido. Rio de Janeiro, Jorge Zahar, 2003.

BRANDÃO, Elaine Reis. Revelação da gravidez na adolescência em famílias de camadas médias: tensões e dilemas. In: HEILBORN, Maria Luiza et alii. (orgs.) Sexualidade, família e ethos religioso. Rio de Janeiro, Garamond, 2005, pp.111-134.

BRUCKNER, Pascal. A euforia perpétua: ensaio sobre o dever de felicidade. Rio de Janeiro, Difel, 2002.

CHAZAN, Lilian Krakowski. "Meio quilo de gente!" - produção do prazer de ver e construção da pessoa fetal mediada pela ultra-sonografia: um estudo etnográfico em clínicas de imagem na cidade do Rio de Janeiro. Tese de doutorado em Saúde Coletiva, UERJ, 2005.

CONDÉ, Geraldo Garcez. A felicidade mediada: notas para um estudo do imaginário da felicidade na mídia. Trabalho apresentado na VII Reunião de Antropologia do Mercosul (RAM), Porto Alegre, 2007.

DIAS, Acácia Batista. Parentalidade juvenil e relações familiares em Salvador, BA. Tese de Doutorado em Ciências Sociais, UERJ, 2005.

ECO, Umberto. Apocalípticos e integrados. São Paulo, Perspectiva, 1979.

EDMONDS, Alexander. No universo da beleza: notas de campo sobre cirurgia plástica no Rio de Janeiro. In: GOLDENBERG, Mirian. (org.) $\mathrm{Nu}$ \& vestido. Rio de Janeiro, Record, 2002, pp.189-261.

EliAS, Norbert. O processo civilizador. Rio de Janeiro, Jorge Zahar, 1990.

FEATHERSTONE, Mike. The body in consumer culture. In: FEATHERSTONE, Mike et alii. (orgs.) The body: social process and cultural theory. Londres, Sage, 1991, pp.170-196.

FouCAult, Michel. Vigiar e Punir. Petrópolis, Vozes, 1977.

. A História da sexualidade 1. Rio de Janeiro, Graal, 1997. 
Um estado emotivo: representação da gravidez na mídia

FRANKLIN, Sarah. Making sense of missed conceptions: anthropological perspectives on unexplained infertility. In: LAMPHPERE, Louise, RAGONÉ, Helena e ZAVELlA, Patricia. (orgs.) Situated lives: gender and culture in everyday life. Londres, Routledge, 1997, pp.99-109.

GIDDENS, Anthony. Modernity and self-identity. Oxford, Polity Press, 1991.

- A transformação da intimidade: sexualidade, amor $e$ erotismo nas sociedades modernas. São Paulo, Editora da UNESP, 1993.

JUER, Ester. O mau humor da TPM: uma interpretação do feminino. Tese de Doutorado em Ciências Sociais, UERJ, 2007.

LoBiAnCo, Anna Carolina. A psicologização do feto. In: FigueIRA, Sérvulo. (org.) Cultura da psicanálise. São Paulo, Brasiliense, 1985, pp.94-115.

LUNA, Naara. Provetas e clones: uma antropologia das novas tecnologias reprodutivas. Rio de Janeiro, Editora Fiocruz, 2007.

LUTZ, Catherine. Unnatural emotions. Chicago, University of Chicago Press, 1988.

. Engendered emotion: gender, power, and the rhetoric of emotional control in American discourse. In: LUTZ, Catherine e ABULUGHOD, Lila. (orgs.) Language and the politics of emotion. Cambridge, Cambridge University Press, 1990, pp.69-91.

MARTIN, Emily. The fetus as intruder: mother's bodies and medical metaphors. In: DAVIS-FLOYD, Robbie e DUMIT, Joseph. (orgs.) Cyborg babies: from techno-sex to techno-tots. Londres, Routledge, 1998, pp.125-142.

. A mulher no corpo: uma análise cultural da reprodução. Rio de Janeiro, Garamond, 2006.

MAUSS, Marcel. Sociologia e Antropologia vol.II. São Paulo, EPU, 1974.

MELO, Mariana Leite de. Dois pesos e duas medidas: "ser gorda" e os vigilantes do peso. Dissertação de Mestrado em Ciências Sociais, UERJ, 2004. 
MitChell, Lisa M. e GeORGES, Eugenia. Baby's first picture: the cyborg fetus of ultrasound imaging. In: DAVIS-FLOYD, Robbie e DUMIT, Joseph. (orgs.) Cyborg babies: from techno-sex to techno-tots. Londres, Routledge, 1998, pp.105-124.

ORTEGA, Francisco. Das utopias sociais às utopias corporais: identidades somáticas e marcas corporais. In: ALMEIDA, Maria Isabel Mendes e EuGÊNIO, Fernanda. (orgs.) Culturas jovens: novos mapas do afeto. Rio de Janeiro, Jorge Zahar, 2006, pp.42-58.

ORTNER, Sherry. Está a mulher para o homem assim como a natureza para a cultura? In: ROSALDO, Michelle e LAMPHERE, Louise. (orgs.) A Mulher, a Cultura e a Sociedade. Rio de Janeiro, Paz e Terra, 1979, pp.95-120.

PAIM, Heloisa Helena Salvatti. Marcas no corpo: gravidez e maternidade em grupos populares. In: DUARTE, Luiz Fernando Dias e LEAL, Ondina Fachel. (orgs.) Doença, sofrimento, perturbação: perspectivas etnográficas. Rio de Janeiro, Editora Fiocruz, 1998, pp.31-47.

RAGONÉ, Helena. Chasing the blood tie: surrogate mothers, adoptive mothers and fathers. In: LAMPHERE, Louise, RAGONÉ, Helena $e$ ZAVElla, Patricia. (orgs.) Situated lives: gender and culture in everyday life. Londres, Routledge, 1997, pp.110-127.

RAPP, Rayna. Refusing prenatal diagnosis: the uneven meanings of bioscience in a multicultural world. In: DAVIS-FLOYD, Robbie e DUMIT, Joseph. (orgs.) Cyborg babies: from techno-sex to techno-tots. Londres, Routledge, 1998, pp.143-167.

REZENDE, Claudia Barcellos. Ansiedade e medo na experiência da gravidez. Trabalho apresentado na VIII Reunion de Antropologia Del Mercosur (RAM), Buenos Aires, 2009.

ROHDEN, Fabíola. Histórias e tensões em torno da medicalização da reprodução. Gênero, vol. 6, n¹, Niterói-RJ, Editora da UFF, 2006, pp.213-224.

RÜDIGER, Francisco. Literatura de auto-ajuda e individualismo: contribuição ao estudo da subjetividade na cultura de massa contemporânea. Porto Alegre, Editora da UFRGS, 1996. 
Um estado emotivo: representação da gravidez na mídia

SALEM, Tânia. Manuais modernos de auto-ajuda: uma análise antropológica sobre a noção de pessoa e suas perturbações. Série Estudos em Saúde Coletiva, n 7, Rio de Janeiro, IMS/UERJ, 1992, pp.1-37.

- O Casal grávido: disposições e dilemas da parceria igualitária. Rio de Janeiro, Editora FGV, 2007.

SCAVONE, Lucila. Maternidade: transformações na família e nas relações de gênero. Interface, vol.5, nº 8, 2001, Botucatu, UNESP, pp.47-60.

SCHNEIDER, David. American kinship: a cultural account. $2^{\mathrm{a} e d .}$ Chicago, The University of Chicago Press, 1968.

SonTAG, Susan. A doença como metáfora. Rio de Janeiro, Graal, 1984.

STRATHERN, Marilyn. Necessidade de Pais, Necessidade de Mães. Estudos Feministas, 3 (2), Florianópolis-SC, 1995, pp.303-329.

TORNQUIST, Carmem Susana. Parto e poder: o movimento pela humanização do parto no Brasil. Tese de Doutorado em Antropologia Social, Universidade Federal de Santa Cantarina, 2004.

VARGAS, Elaine e RUSSO, Jane. Desejo de filhos e ideal de maternidade um estudo da maternidade e da gravidez na mídia. Trabalho apresentado na VI Reunião de Antropologia do Mercosul, Montevidéu, Uruguai, 2005. 